\title{
Comprehensive Search Engine Optimization Model for Commercial Websites: Surgeon's Website in Sydney
}

\author{
MdSaidul Hoque ${ }^{1}$, Abeer Alsadoon¹, Angelika Maag1, P. W. C. Prasad ${ }^{*}$, Amr Elchouemi² \\ ${ }^{1}$ School of Computing and Mathematics, Charles Sturt University, Australia. \\ ${ }^{2}$ Ashford university, San Diego, California, USA \\ *Corresponding author. Tel.: 61292919356; email: cwithana@studygroup.com \\ Manuscript submitted June 10, 2017; accepted August 28, 2017. \\ 10.17706/jsw.13.1.43-56
}

\begin{abstract}
Build a Search Engine Optimisation (SEO) model, to improve organic ranking and traffic to the commercial websites is the purpose of this study. Four search engine optimisation strategies - content, link building, social presence and online reputation are applied to a Sydney based oral and maxillofacial surgeon's website to improve its ranking in the organic search results. Google analytics and search engine tools are used to track organic traffic and organic ranking of the website. This study shows that keywords in the Meta description, content related headings, longer and unique content with useful information, webpage loading speed, SSL certificates, mobile responsiveness of a website, Links to relevant local sites and online reputation improve organic ranking and organic traffic to websites. This study, content length, keyword density, SSL certificates, relevant local link building and online reputation are used to improve the SEO of websites.
\end{abstract}

Key words: Search engine optimisation, organic ranking, organic traffic, google analytics tool, online reputation, link building, on-page SEO, site structure, social sharing.

\section{Introduction}

SEO is one of the most common methods for online marketing [1]. The main aim of SEO is to achieve positioning on the first page of the search engine results page through specific terms that drive traffic from search engines to a website [2]. There are some onsite and offsite factors which decide the ranking of a website on the search engine result page for a specific term [1]. Onsite factors are related to content, website structure and HTML of the website [3]. Offsite factors are affected by to link building, social presence and customer feedback [3]. There are more than 200 onsite and offsite factors which control the ranking of a website on a search engine results page [4], divided by researchers and industry experts into three categories - content, link building and social sharing [2].

For the current best solution, researchers have suggested a focus on blog comments, forum links, adding keywords into heading tags [2], and increasing keyword density of the content [5]. However, Search Engine Optimisation Starter Guide [6] has suggested that such factors should be avoided as they tend to negatively impact ranking. Moreover, Google and other search engines change their algorithms frequently and introduce new SEO factors. The most recent academic SEO research was carried out in 2016 - almost 1 year ago. Within the last 12 months Google has updated its algorithm 8 times. Moreover, the current solutions do not offer suggestions for the improvement of website rankings for a specific location or region, particularly for oral and maxillofacial surgeons in Sydney. 
There is significant interest in oral and maxillofacial surgery. Particularly in Sydney, as individuals are gradually becoming more conscious of the importance of oral health. More Sydney residents are now searching online for information about oral and maxillofacial surgery, a potential source of new patients for this type of business. However, many surgeons are not increasing their clientele through website marketing due to an inappropriate SEO. In this research, an enhanced comprehensive SEO model has been developed which will assist surgery websites (here based in Sydney, in particular those of oral and maxillofacial surgeons. The ultimate aim is to better position these websites' organic search results and draw more clients to their business. Current SEO solutions are generic. No academic research has been done as yet on SEO for the oral and maxillofacial surgery industry. Furthermore, academic researchers have so far not addresses how to improve a website for specific locations or regions. In our research, we propose a comprehensive SEO model for Sydney based oral and maxillofacial surgeons. This will help other surgeons, doctors and dentists to improve their websites for a specific location to increase clientele. Objectives of this research are an enhanced and comprehensive Search Engine Optimisation model will be developed for the websites of Sydney based oral and maxillofacial surgeons, integrating new SEO factors, the impact of the strategies of the new SEO on organic ranking of a website will be examined, and The relationship between organic ranking and organic traffic of a website will be probed.

\section{Related Work}

\subsection{Search Engine Optimization}

SEO is a method to improve a website in a specific way so that it achieves top position on the Search Engine Result Page (SERP) for specific search terms or keywords. A website can be improved through onsite and offsite optimisation [5]. Onsite optimisation is done by improving content quality, website structure and HTML of the website [2]. Content quality of a webpage depends on content length, formatting of content, content relevance to the topic and the addition of other elements (images, tables, videos, etc.) to the content [3]. The user experience of a website depends on the navigation system of website, its design or structure and the webpage loading speed [7]. There are some elements on a website which are always important for making a website search engine friendly. These include the title tag, Meta tags, and the sitemap and robots.txt files [1]. Offsite optimisation consists of creating backlinks on other websites, social sharing [2] and getting positive feedbacks from customers through local business directories [8].

According to Lee and Jang [9], an SEO strategy should be based on three criteria. Those are improving accessibility to the website for the search engines, increasing relevance between site content and keywords, and improving site credibility. However, there is no mention of off-page optimisation of a website in this research. Similarly, Killoran [4] identified how search engine techniques can be used to increase the visibility of a website. He emphasised the importance of the selection of keywords, adding keywords to web text, establishing inbound links by publishing content on other websites and social sharing, all of which will improve the organic ranking of a website. However, there was no reference to the website structure or HTML

Gudivada, Rao and Paris [1] divided the SEO strategy into two categories - on- and off-page optimisation. According to their research, title tag and Meta description optimisation, selection of keywords, navigation of the website, privacy policy and the custom 404 page of a website belong to on-page optimisation. Quality link building, robots.txt and the sitemap are part of off-page optimisation. A limitation of this research arises from a lack of discussion of content quality of a website, which is important for on-page SEO [4].

\subsection{State of Art Search Engine Optimization}

Zhang and Cabage [2] investigated various websites to determine which strategies improved the ranking 
of a website on the Google search engine result pages. They found that the content of a website, link building and social sharing improves the ranking of a website in terms of the Google search engine result page for targeted keywords.

\subsection{Content}

According Zhang and Cabage [2], content consists of three elements, onpage SEO, site structure and quality content.

\section{On-page SEO}

Keyword Research: Keyword research is one of the most important, valuable and high return activities in search engine optimisation [7]. Selecting appropriate keywords for a website helps to get targeted traffic which is likely to increase revenue. Google Adword Keyword Planner, Moz Keyword Explorer, SEMRUSH Keyword Analytics and Microsoft Bing Ads Intelligence are the effective tools for keyword research. According to Zhang and Cabage's SEO model, the first step in on-page SEO is finding appropriate keywords as illustrated in figure-1. Well-chosen keywords lead to higher ranking of a website in organic search results.

Keywords in the Title Tag: The Title Tag of a webpage communicates the topic of a website to users and search engines [6]. The title tag is the HTML tag which appears at the head section of a website. When a webpage materialises in an organic search result, the title tag usually appears in the first line of the search result. Zhang and Cabage [2] emphasised on adding keyword in title tag to improve the organic ranking of a website for targeted keywords.

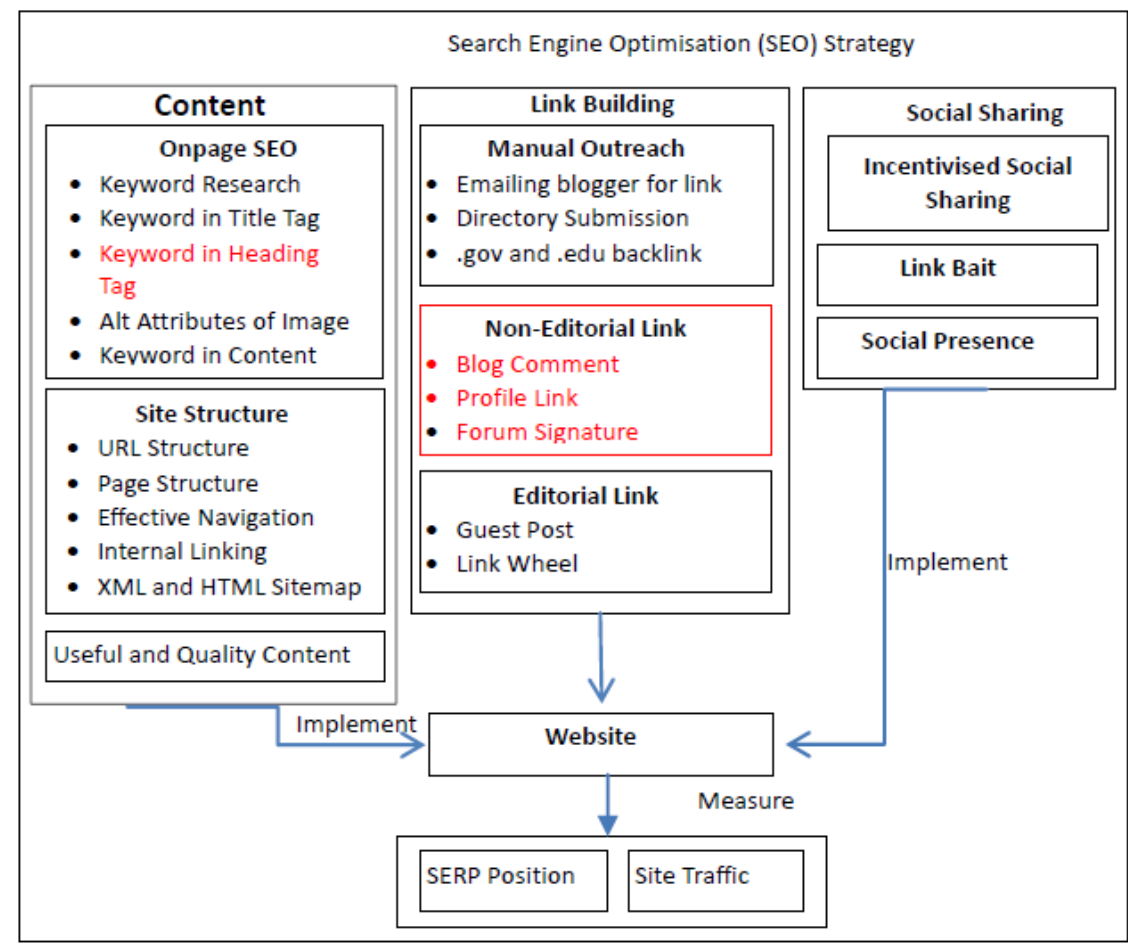

Fig. 1. Current best SEO model with limitation.

Keywords in the Heading Tag: Search Engine marketing company The Webmaster Inc. [10] added keywords to heading tags (h1, h2, h3 etc.). The Webmaster Inc. argued that heading tags are used to express the main topic of the page. Heading tags should be used to emphasise important text in the content [6]. According to Zhang and Cabage's [2] research, adding keywords into heading tags has positive impact on 
the ranking of a website in the organic search result. However, Fishkin [7] and Search Engine Optimisation Starter Guide [6] both state that headings should be relevant to content. The existence of keyword optimised heading tags is often penalised by Search Engines.

Alt Attribute of Image: An alt attribute of an image helps users and search engines to understand the topic of the image. Users and search engines are able to identify the relationship between an image and the content through an alt attribute [11]. Zhang and Cabage [2] investigated alt attributes of images and labelled these a 'reinforcement' of the ranking of a website in organic search results.

Keyword in the Content: Cchanda [11] and Fishkin [7] both have given importance to adding keywords into the content. Adding keywords to content indicates that the content topic has a relationship with the keyword. Zhang and Cabage [2] have found that adding keywords in content improves the onpage SEO of a website which ultimately positively affects the organic ranking of a website.

\section{Site Structure}

URL Structure: A URL is readable text that identifies the structure of the give website. As the URL is an important part of search engine optimisation, it should be easy to read and relevant to the topic of the content [5], [9]. According to the Search Engine Optimisation Starter Guide [6], if a URL contains relevant words, these will provide users and search engines with more information about the page than an ID or an oddly named parameter would. Zhang and Cabage [2] have emphasised the importance of improving URL structure by adding keywords which makes the website structure more user-friendly.

Page Structure: According to a study by Zhang and Cabage [2], well-structured pages including sections and categories help users to find important pages with ease. This improves the site structure and makes it user friendly which improves the ranking of a website in organic search results.

Effective Navigation: Zilican and Gregus [5] and James [12] have provided an overview of how effective navigation makes a site structure user-friendly. They have pointed out that the main advantage lies in quick and easy navigation from one page to another. Zhang and Cabage [2] have also mentioned that effective navigation can get a user to any page in the site with fewer clicks.

Internal Linking: The Search Engine Optimisation Starter Guide [6] advocates that webmasters need to focus attention on internal linking which can help users and search engines to navigate a site better. Zhang and Cabage [2] have demonstrated that internal linking is an important factor for the improvement of the site structure.

XML and HTML Sitemap: According to Cchanda [11], Gudivada, Rao and Paris [1], XML and HTML sitemaps help users and search engine crawlers to isolate anything on a website quickly. Zhang and Cabage [2] have mentioned that using standard HTML and XML sitemaps can further ensure that search engines quickly and accurately account for all of the website content.

\section{Useful and Quality Content}

According to Zilincan and Gregus [5] and Gudivada, Rao and Paris [1], creating compelling and useful content is the most important factor in terms of the ranking of a website in organic search results for a keyword. According to Zhang and Cabage [2], useful, high quality content can improve the organic ranking of a website by $38 \%$...

\subsubsection{Link building}

Zhang and Cabage [2] identified three methods for link building, Manual outreach, non-editorial link and editorial link.

Manual Outreach: Dean [13], Cchanda [11] and Grabowski [14] emphasised the importance of manual outreach link building. According to their studies, link from .gov and .edu websites, directory submissions and getting links from blog are always considered high quality link building. These links boost the ranking of a website quickly. In Zhang and Cabage's research, these three types of links have been added into the 
model to improve the organic ranking of a website

Non-Editorial Links: Creating links by posting comment on blogs, creating profiles and adding links on forum signature are known as non-editorial backlinks as presented in figure-1.

Editorial Links: Editorial backlinks consist of posting content on other websites for link building. Getting links from other websites by posting contents improves link quality and diversity. These links reinforce the organic ranking of a website [14]. According to Figure-1, there are two ways to create editorial links, through guest posting and through link wheel. Guest posting means posting content on the websites of others and thus establish links. Link wheel consists of setting up micro blogs (such as blogger, WordPress and Tumblr) and create links by posting content on these micro blogs.

\subsubsection{Social sharing}

Link Bait: This involves creating share-worthy content (e.g., articles, video, Infographics, apps) on the primary (internal) website, and then sharing the content via links, images, or quotes with (external) social platforms such as Twitter and Facebook, while crediting the content creator and the site from which it originates. Sharing contents on social networking websites helps to build traffic for a website [14]. When the content of a website is shared by many users, search engines consider it as having important and useful content. As a result, the webpage containing the content ranks better than other webpages [5]. According Zhang and Cabage [2], link baits or sharing contents on social networking sites adds importance to the content of a website for users and search engines. This helps to improve organic ranking of a website.

Social Presence: Creating official accounts or pages on social networking sites (Facebook, Twitter and Instagram) is known as social presence. Social presence proves that a website is operated by a real organisation, and the services and products offered by the website are reliable. Google does not rank a website if it looks like a scam website [14]. According to Zhang and Cabage [2], social networks influence Google directly and indirectly. Having a social presence on social networking sites provides a link to a website which is of direct benefit.

Incentivised Social Sharing: Publishing and promoting content through ads on social networking sites is known as incentivised social sharing. According to Zhang and Cabage [2], incentivised social sharing revives a website and creates a social impact across multiple platforms including the ranking in organic search result.

\subsection{Limitation of the State of Art Solution}

Figure-1 shows the limitations of this solution (red). Zhang and Cabage [2] have suggested that adding keywords into heading as a part of on-page SEO is advantages, although that is not always possible. They point out the importance of adding keywords into headings in service pages or 'contact us' pages. In the service page, the name of the service should be in the heading. In Fig. 1, blog comments, profile links and forum signatures are mentioned as non-editorial links. These links have been already considered as spam link. According to the Search Engine Optimization Starter Guide, These types of backlink cause penalty from search engines [11].

Furthermore, Zhang and Cabage [2] divided the SEO strategy into three segments. They identified which features controlled each segment. However, they have not identified additional activities for Geo targeted keywords like 'Oral and Maxillofacial Surgeon Sydney'. In this solution, there is no mention of how to optimise a website structure, the on-page SEO or the content of a website to rank well on the Google search engine results page for location-based keywords. They have not even mentioned anything about adding a physical address of a business to the website. There was also no discussion of Customer feedback on local directories. 


\section{Proposed Model for Commercial Websites}

\subsection{Research Proposed and Hypothesis}

The main objective of this study is to develop an enhanced SEO model and test the impact of the model on the organic ranking and traffic of a website. For the proposed models, new factors are added. In this study, we shall also examine how these new factors improve the model and impact the organic ranking of the targeted website.

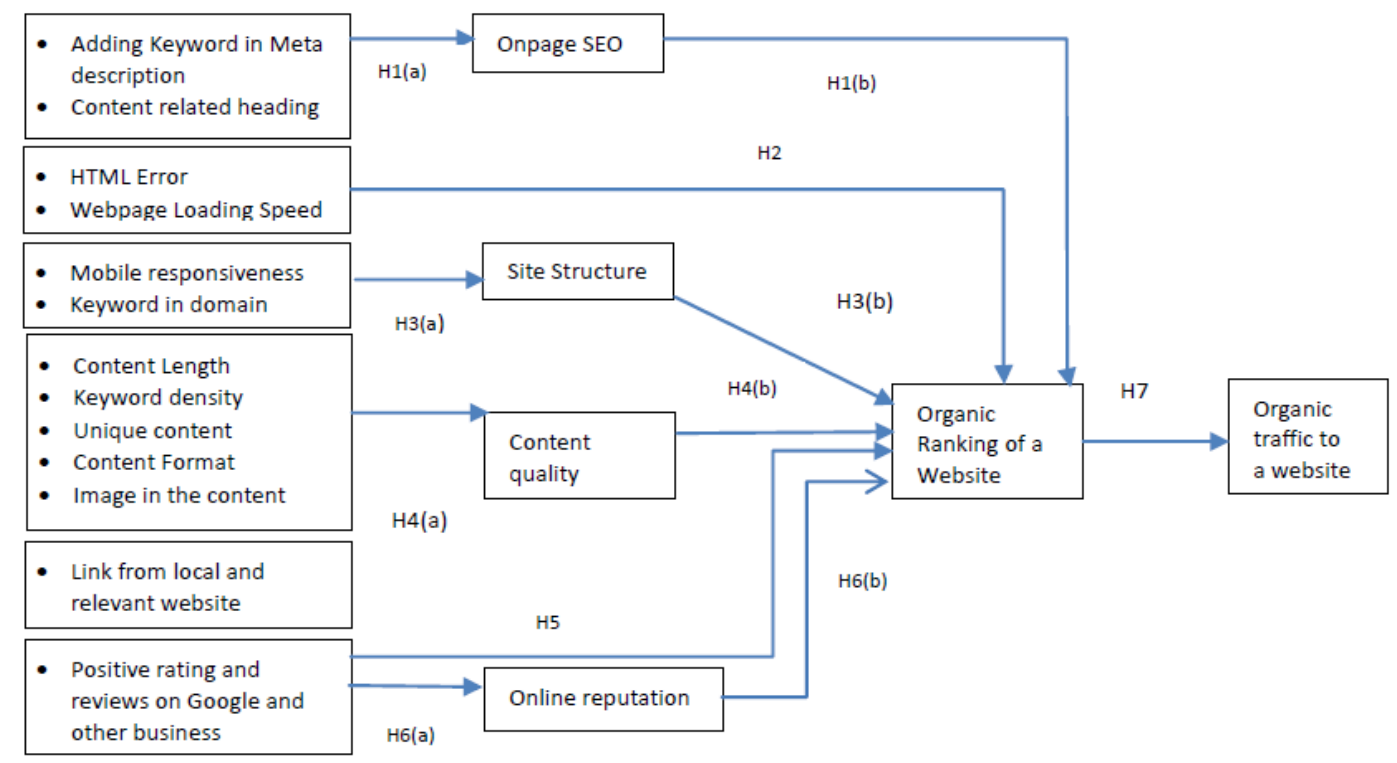

Fig. 2. Proposed hypothesis.

The following hypotheses are tested below and simulated in Fig. 2:

Hypothesis 1(a): Adding keyword to the Meta description and content related heading improves the onpage SEO of a website;

Hypotheis 1(b): Organic ranking of a website depends on the improvement of the onpage SEO of the website.

Hypothesis 2: The HTML error and webpage loading speed impact on the organic ranking of a website; Hypothesis 3(a): Mobile responsiveness and keywords in the domain name improve site structure; Hypothesis 3(b): Improved Site structure has positive impact on the organic ranking of a website;

Hypothesis 4(a): Length, uniqueness, keyword density and format of content control the quality of the content;

Hypothesis 4(b): High quality content boosts the e-organic ranking of a website for targeted keywords; Hypothesis 5: Links from local and relevant websites have positive impact on the organic ranking of a website;

Hypothesis 6 (a): Positive ratings and reviews by Google and other business directories improve online reputation;

Hypothesis 6 (b): If the Online reputation of a website improves, organic ranking of the website will improve for the location based keywords;

Hypothesis 7: Organic ranking of a website is proportional to organic traffic to a website.

\subsection{Research Proposed and Hypothesis}

Our proposed comprehensive SEO model in figure 3 has four strategies. Those are - content, Link Building, Social Sharing and Online reputation. 


\section{Content}

\subsubsection{Content}

\section{Onpage SEO}

From Zhang and Cabage's research [2], it has been found that the title tag, the alt attribute of an image and the keywords in the content improve the onpage SEO of a website. In addition, two other factors are essential to the improvement of the onpage SEO of a website. Those are content-related Headings and Keywords in the Meta description.

Content related headings: According to the Search Engine Optimisation Starter Guide [6], headings (h1, h2, h3 and h4) should be relevant to the content so that readers and search engines can understand the content easily. Content related headings explain each section of the content. They create links between each section of the content which makes the content user- and search engine friendly. For our proposed model, the heading of the homepage is 'Oral and maxillofacial Surgeon Sydney' and the heading of the 'Dental Implant' page is 'Dental Implant Procedure'.

Keywords in the Meta description: The Meta description is an important element of a website which appears in the organic search results [6]. Using keywords in the Meta descriptions indicates that the content on the webpage is related to the keywords [5]. When search engine crawlers visit a website, they initially crawl the title tag, the Meta description and the URL. Therefore, adding keywords in the Meta description helps a website rank higher due to an added keyword. Here is the Meta description for our proposed model

"Dr ............. is an oral and maxillofacial surgeon in Sydney who has been performing oral and maxillofacial Surgery in Sydney since ........."

Site Structure

According to Zhang and Cabage's [2] research, the page structure, the URL structure, the XML and HTML sitemap, internal linking and effective navigation are the factors that improve site structure. In our proposed model, we added four factors. An SSL certificate, mobile responsiveness, webpage loading speed and HTML error.

SSL Certificate: SSL stands for Secure Socket Layer, a standard encryption technology used to transfer data from a user's browser to the web server. Websites use SSL encryption to prevent hackers to intercept and misuse the data users leave on a website. Search engines give priority to websites with an SSL certificate for reasons of safety of the [15]. When a website has an SSL, it encrypts all user data to protect it from unwanted intrusion. It makes a website user-friendly. Search engines always give priority to websites which are user friendly. An SSL was installed in our targeted website. As a result, the website url changed from http:// to https://.

Webpage Loading Speed: According to Fishkin [7] and Dean [16], the webpage loading speed is an important search engine ranking factor. Users like to visit webpages which load faster. Thus, webpages that load faster usually rank on the first page of search engine result pages. Our proposed model recommends that the webpage loading speed score must be 80 out of 100 .

HTML Error: If the HTML error of a website is high, it indicates that the website is not designed appropriately. Webpages which rank on the first page of organic search results usually have a low number of HTML error [11], [15], [4]. The website which has high density of HTML errors generally has errors in the source code reducing website security. This means it can easily be hacked. For this reason, search engines assign low priority to the websites which have a high number of HTML errors. For the proposed model, the number of HTML errors on each page cannot be more than 5 .

Mobile Responsiveness: Using a mobile responsive website structure makes a website mobile friendly. Mobile users can read contents of a website with ease. This has led Google to consider this as a search 
engine ranking factor [13] [11], [10]. Here are the desktop and mobile versions of a websiteUseful and high Quality Content

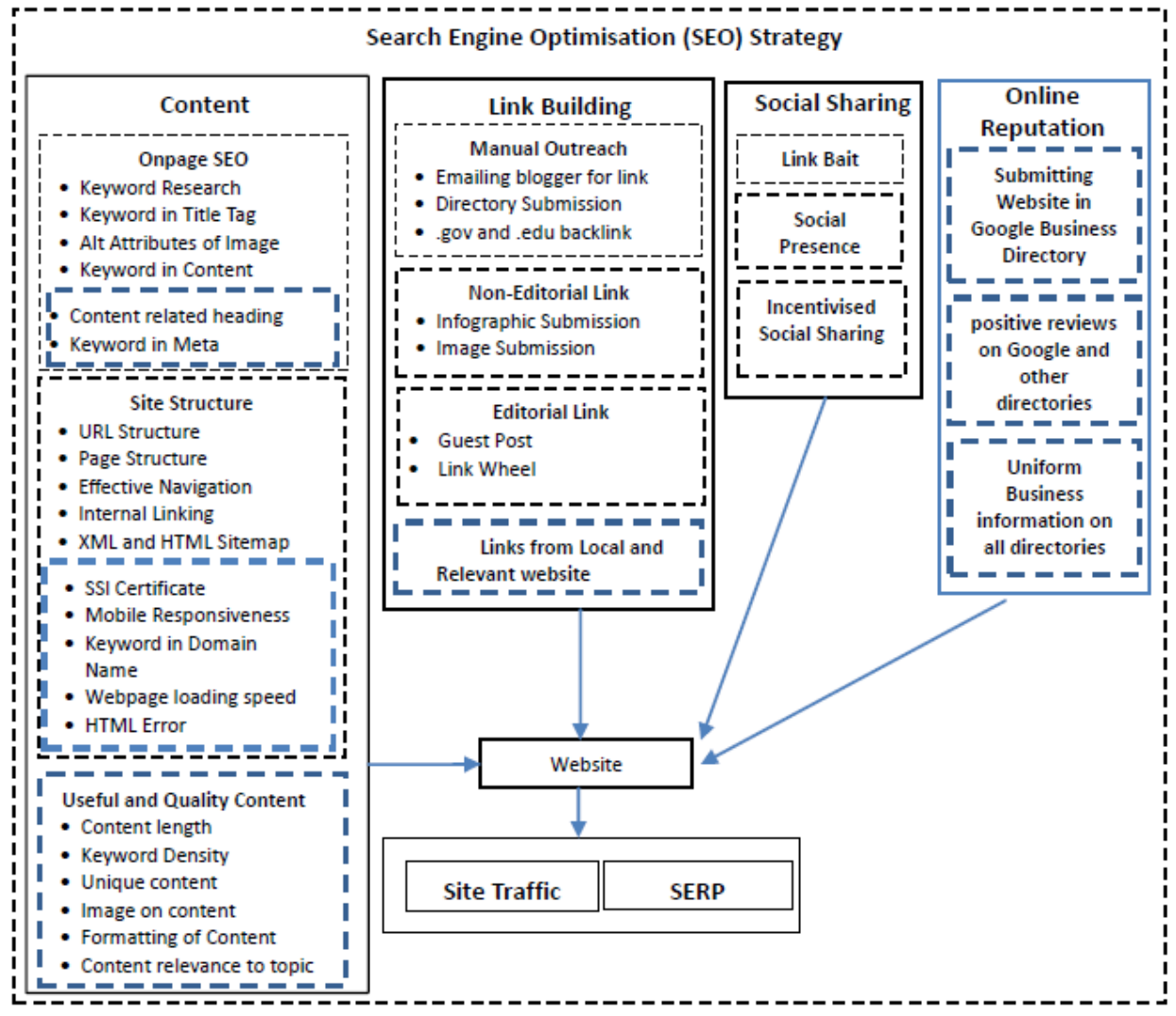

Fig. 3. Proposed comprehensive SEO model.

Zhang and Cabage [2] have mentioned only useful and quality content in their model. However, they have not described how to create quality in terms of content and make it useful. Zilican and Gregus [5], and Dean [16] and James [12] have identified several factors that make content useful and enhance quality c.

Content Length: Webpages with longer content (more than 1000 words) usually rank first in Google [16]. Longer content ensures that topics are well covered enhancing usefulness. [12]. It is easy to add more useful information in longer content. Users love to read and share content which has useful information [2]. Therefore, this kind of content is preferred by search engines which in turn ranking over webpages which have little content. For our targeted website, content of each webpage is more than 500 words.

Image on the Content: Dean et al. [16] analysed content and found that image-based content usually ranks higher than that without images. This is because images are effective for attracting the attention of readers, often helping readers to understand the content. Usually low quality content does not have images because this type of content is not written for users. Adding images proves that the author or publisher is eager to make this content user friendly [6]. When content of a webpage becomes user friendly, it gets top priority from search engines. A successful website has at least one image on each page.

Keyword Density: Dean [16], Chanda [11] and James [12] have analysed the effects of keyword density on ranking. They found that $2-3 \%$ keyword density has positive impact on organic ranking. However, keyword density of more than $3 \%$ has negative impact. For the proposed model keyword density of $1-2 \%$ is recommended.

Content relevance to topic: Discussing a topic briefly makes content relevant to the topic and provides it with a higher ranking than websites with less content. [12]. If content is not relevant to the topic, it has no 
chance to rank for targeted keywords in organic search results.

Formatting content: Content must be formatted by adding headings tag, bold and italic tags and a CSS stylesheet. Well formatted content is more readable and readers and search engines find it easier to understand [12]. Well formatted content is a sign of quality. Contents which are written for spamming or for generating links are generally not formatted appropriately [11]. A webpage which has quality content is usually formatted appropriately so that it is reader friendly. When a webpage has quality and reader friendly content, it ranks better in organic search results for targeted keywords. The proposed model adds $\mathrm{h} 1, \mathrm{~h} 2, \mathrm{~h} 3$, bold, italic and table tag to format the content.

\section{Link Building}

Zhang and Cabage [2] incorporated 5 types of link building in their model, .gov and .edu, backlink, directory submission, blog link, guest post and Link wheel. For the proposed model, these linking devices have been used. Furthermore, apart from these links, a further four link building mechanisms have been incorporated, Infographic submission, PPT submission, Image submission and links from relevant, local websites

Infographic Submission: According Cchanda [11], Infographics are the best way of link building aiding in getting linked to high quality and well-known websites which in turn improves the ranking of a website.

Image Submission: Submitting images on well-known websites like Pinterest, flicker and imager also generate high quality links which improves the link diversity of a website. Several types of link building improve the traffic to and therefore the ranking of a website [11] [13]. The proposed model submits useful images to other websites which will bring more traffic. Moreover, it improves the quality of link profile of a website.

Links from relevant and local websites: Backlink from local and relevant websites sends a strong signal to the search engine [8]. Establishing links to local websites helps a website to rank for specific location. Links from relevant websites prove that the targeted website is relevant to the keyword. Our SEO model proposes to obtain links to dental, medical and health related websites including backlinks from .com.au websites.

\section{Online Reputation}

A high online reputation is essential for optimising a website for certain locations [8]. Shaw [14] from the Search Engine Marketing company Mozz Inc. disc overed a relationship between online reputation and organic ranking with importance of online reputation in organic ranking increasing in 2017. Submission of a website to Google business directories, positive reviews by Google and other business directories and uniform business information helps to build improved online reputation.

Submitting a Website to Google Business Directories: Having submitted a website to a Google business directory proves that the website is representing a real business. This earns the trust of users which is essential for organic ranking [8]. The Google business directory is managed by Google. Any business added to this directory appears in Google Maps. Customers can also provide feedback which will help build online reputation. For the proposed model, the website under research will be submitted to on Google Business directory (http://www.google.com/business).

Positive reviews in Google and other business directories: Positive reviews from previous clients enhance the reputation of a business. If a business has well regarded for its services, its website will rank better in organic search results [8]. Positive reviews and ratings improve the organic ranking of a website [14].

Positive reviews from old clients also prove that the services or products provided by the website are good and trustworthy. These positive reviews bring new customers to the business. For the proposed model, the aim is to get positive reviews by Google and other oral surgeon directories such as dentist.com.au, healthshare.com.au, healthengine.com.au and truelocal.com.au 
Uniform Business Information in all Directories: The contact address of a business must be same on the website and all business directories. Otherwise, it will create confusion among users and search engines. Variations in the business address between a website and business directories affect organic ranking negatively [8].

For the proposed model, the same contact address will appear on the targeted website, Google and other business directories.

\section{Discussion and Evaluation}

To implement the proposed model, a new demo website was designed with a demo web address. The proposed strategies were applied over a period of 8 weeks. The impact on organic ranking and organic traffic of the website was checked throughout the 8 weeks, and the final results have presented in figure 4 and 5.

\subsection{Applying All Factors Listed in the Proposed Model}

The Google Keyword Planner tool was used to identify the most suitable keywords for the website which was oral and maxillofacial surgeon Sydney. To begin with, the onpage SEO of the website was improved by adding each factor illustrated in figure-3. The selected keyword was added in the title tag and Meta description of the website. Content related h1 heading tags were added on all webpages.

To improve site the structure, the URL structure was upgraded through the addition of a meaningful word. The page structure of the website was changed by adding sections and subsections. An effective navigation menu was added to the top and bottom of the website. Internal linking was done between posts and pages. An XML Sitemap was added to the website. The XML sitemap is a list of all pages available on a website. This list is usually created using XML markup language. This XML format is important as Search engines use XML markup language to crawl a website. An SSL certificate and a mobile responsive theme were installed on the website. Webpage loading speed was increased while simultaneously the number of HTML errors was reduced.

High quality and useful content was added to all webpages. Content length of each webpage was more than 500 words. Content of each webpage had h1, h2 and h3 headings, tables and bullet points. Important words were formatted with italic and bold tags. Each content page was checked with the Cityscape tool to identify uniqueness and remove duplications. Keyword density of all content was $2 \%$.

Inherent in the proposed model, there are four types of link building, Manual Outreach, Non-editorial link, Editorial link and links from local and relevant websites. It was not possible to establish backlink for the website through manual outreach because it was a demo website. Moreover, it did not represent any genuine business. For this reason, we only got non-editorial link, editorial link and links from local and relevant websites.

Social Sharing is another part of the proposed SEO strategy. Initially an account on Facebook and Google Plus was created, to ensure a social presence for the website. Furthermore, blog posts on our website were shared on Facebook and Google Plus. After sharing these, Facebook ads were run for those blog posts as part of incentivised social sharing.

For online reputation, we submitted our website to the Google business directory adding the address from 'Contact Us' page of our website. Then, three positive reviews were posted in the Google business directory to improve the online reputation on our website.

\subsection{Results and Analysis}

We applied the above factors to the website and checked the organic ranking for the keywords 'oral and maxillofacial surgeon Sydney'. We checked the organic ranking of the website on Google Manually. We used 
Google Analytic tool to check the organic traffic to the website. The Relation between Organic Ranking and Organic Traffic has presented is table 1, and the hypothesis results have presented in table 2.

\section{Organic Ranking}

We checked the organic ranking of the website for the selected keywords on Google search engine. We checked the ranking before and after applying each factor. At the beginning, the organic position of the website on the Google search engine for the keywords was 220th. After adding keyword in title tag, organic ranking of the website changed to 212 .

Before installation of an SSL certificate on the website, the organic ranking of the website on Google for the targeted keyword was checked manually. Its position was 163rd in the Google organic search result. After installation of the SSL certificate, the organic ranking of the website changed to 151st. The website was transformed to be compatible with mobile devices, which is known as mobile responsiveness. This mobile response design changed the organic ranking of the website from 151st to 145th. The SSL Certificate and mobile responsiveness improved the organic ranking of the site by $8.18 \%$. Improving Webpage loading speed and decreasing the HTML error improved the ranking to $16.36 \%$ which supports Hypothesis $3(\mathrm{a})$ and 3(b).

Hypothesis 4(a) and 4(b) state that length, uniqueness, keyword density of content, adding images to the content and formatting the content improves the content quality which impacts the ranking of the website. 'Unique content' changed the organic ranking of the website from 109th to 92nd. Increasing content length of the website improved the organic ranking of the website $6.82 \%$. Adding images changed the ranking from 92 to 77. Formatting content i.e. adding bold, italic and header tags in the content also improved the ranking of the website. It changed the organic ranking of the website by $2.73 \%$. However, keyword density did not affect the ranking at all. Editorial backlink ameliorate the ranking by $4.09 \%$. The organic ranking of the website improved by $2.72 \%$ by adding non-editorial links.

Links from local and relevant websites changed the total ranking by $9.55 \%$ which supports our hypothesis 5.

The website was submitted to the Google business directory and three positive reviews were added to improve online reputation. The rating of the website on Google business directory was 5 out of 5 . These two factors changed the position of the website in the Google search engine from 16th to 1st position.

Hypothesis 7 poses that the organic ranking of a website is proportional to the organic traffic of that website. If the improves, organic traffic to the website will also improve. Google Analytics was used to check the volume of organic traffic to the website (Table 2).

From table 2, it is clear that the organic traffic did not increase with the improvement of organic ranking at a certain level. According to Figure 5, organic traffic did not increase though organic ranking of the improved website. In week 6 , the site was ranked in 21 st position in the organic search results which caused a slight improvement in organic traffic. However, there was remarkable improvement in organic traffic in week 7. In week 7, the organic position of the website became 12th and traffic increased to 85.

Table 1. Relation between Organic Ranking and Organic Traffic

\begin{tabular}{|l|l|l|}
\hline Week & $\begin{array}{l}\text { Organic } \\
\text { Position }\end{array}$ & $\begin{array}{l}\text { Organic } \\
\text { Traffic }\end{array}$ \\
\hline Week-1 & 220 & 0 \\
\hline Week-2 & 177 & 0 \\
\hline Week-3 & 109 & 0 \\
\hline Week-4 & 59 & 12 \\
\hline Week-5 & 42 & 13 \\
\hline Week-6 & 21 & 39 \\
\hline Week-7 & 12 & 85 \\
\hline Week-8 & 1 & 192 \\
\hline
\end{tabular}




\section{Impact of Factors on Organic Ranking}

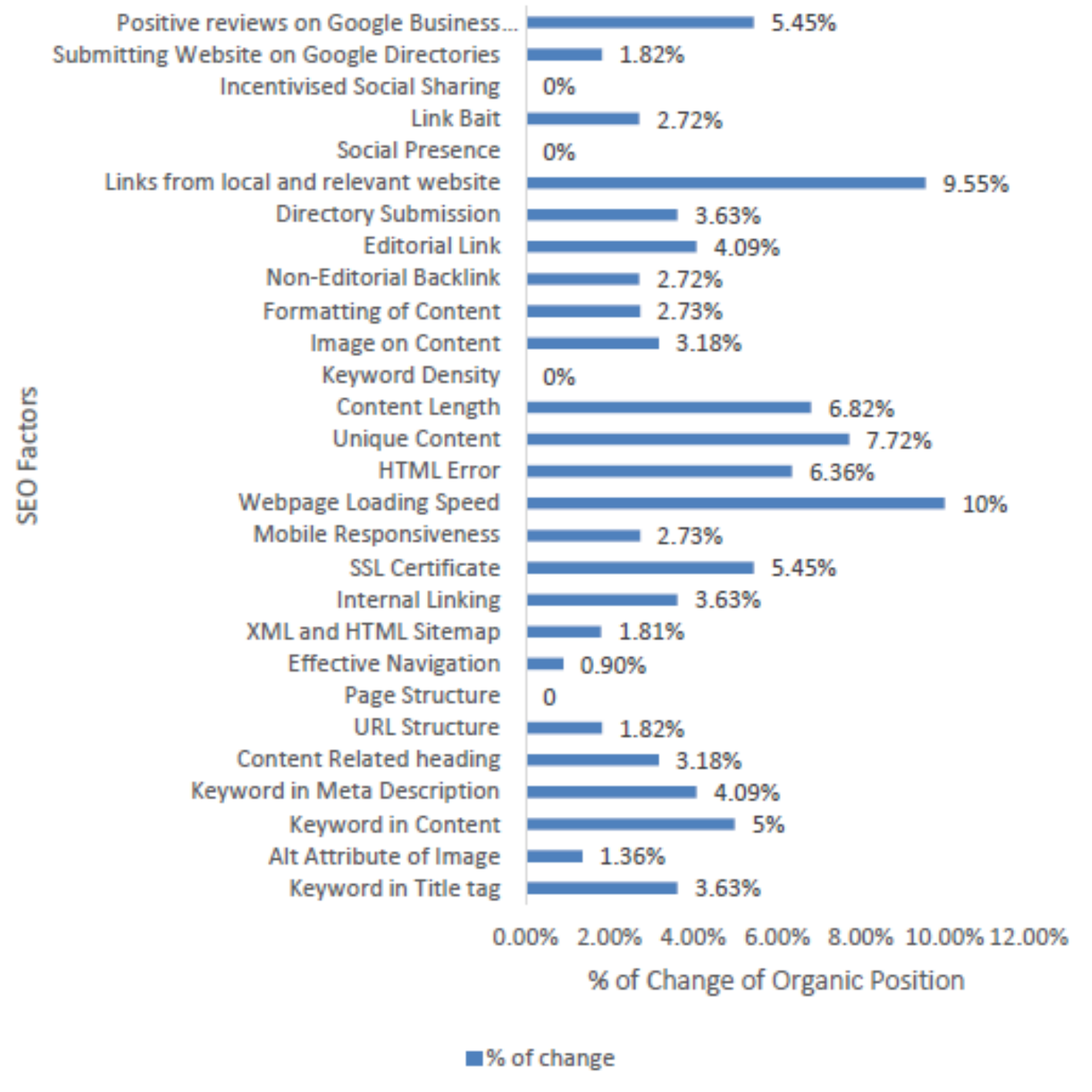

Fig. 4. Relation between SEO factors and organic ranking.

\section{Organic Traffic Vs \\ Organic Ranking}

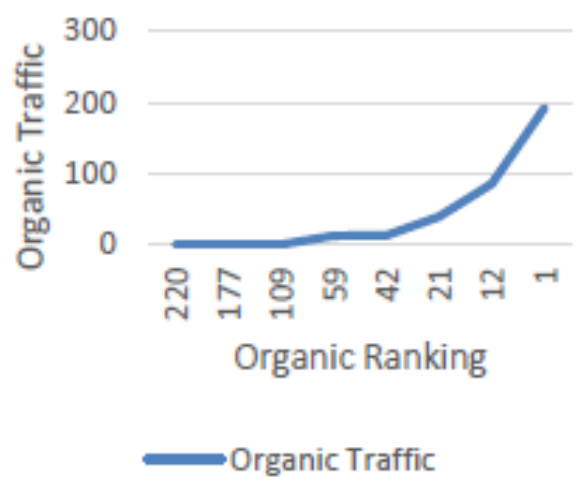

Fig. 5. Relation between organic traffic and organic ranking of a website. 
Table 2. The Hypothesis Result

\begin{tabular}{|c|c|c|}
\hline Hypothesis & KPI results & Supported? \\
\hline $\begin{array}{l}\text { Hypothesis }-1(\mathrm{a}) \text { : Adding keyword in meta } \\
\text { description and content related heading } \\
\text { improves the onpage SEO of a website }\end{array}$ & $\begin{array}{l}\text { Adding keyword in meta description and content } \\
\text { related heading improves on-page SEO of the } \\
\text { website. As a result, it improves the ranking } 7.27 \%\end{array}$ & Yes \\
\hline $\begin{array}{l}\text { Hypotheis-1(b): On-page SEO has proportional } \\
\text { relation with organic ranking of a website }\end{array}$ & $\begin{array}{l}\text { Website ranking advanced } 17.27 \% \text { with the } \\
\text { improvement of on-page SEO. }\end{array}$ & Yes \\
\hline $\begin{array}{l}\text { Hypothesis-2: HTML error and webpage loading } \\
\text { speed have a relation with organic ranking of a } \\
\text { website }\end{array}$ & Organic ranking of the website progressed $16.36 \%$ & Yes \\
\hline $\begin{array}{l}\text { Hypothesis-3(a): Mobile responsiveness and } \\
\text { keyword in domain name improve site } \\
\text { structure. }\end{array}$ & $\begin{array}{l}\text { Adding these two factors improve the site } \\
\text { structure which impacted the organic ranking by } \\
\text { improving } 8.28 \%\end{array}$ & Yes \\
\hline $\begin{array}{l}\text { Hypothesis-3(b): Improved Site structure has } \\
\text { positive impact on organic ranking of a website }\end{array}$ & $\begin{array}{l}\text { According to figure } 4 \text {, Site structure improved } \\
30.88 \% \text { of organic ranking of the website. }\end{array}$ & Yes \\
\hline $\begin{array}{l}\text { Hypothesis-4(a): Length, uniqueness, keyword } \\
\text { density and format of a content control the } \\
\text { quality of a content }\end{array}$ & \multirow{2}{*}{$\begin{array}{l}\text { After adding high quality content, ranking of the } \\
\text { site in organic search result improved } 20.45 \%\end{array}$} & Yes \\
\hline $\begin{array}{l}\text { Hypothesis-4(b): High quality content boosts } \\
\text { the e organic ranking of a website for targeted } \\
\text { keyword }\end{array}$ & & Yes \\
\hline $\begin{array}{l}\text { Hypothesis-5: Links from local and relevant } \\
\text { websites have positive impact on organic } \\
\text { ranking of a website }\end{array}$ & $\begin{array}{l}\text { According to figure } 4 \text {, ranking of the website in } \\
\text { organic search result improved } 9.55 \% \text { after getting } \\
\text { links from local and relevant websites }\end{array}$ & Yes \\
\hline $\begin{array}{l}\text { Hypothesis- } 6 \text { (a): Positive rating and reviews on } \\
\text { Google and other business directories improve } \\
\text { the online reputation }\end{array}$ & $\begin{array}{l}\text { Online reputation score became } 5 \text { out of } 5 \text { after } \\
\text { getting } 3 \text { positive reviews on Google business } \\
\text { directory. }\end{array}$ & Yes \\
\hline $\begin{array}{l}\text { Hypothesis-6 (b): If Online reputation of a } \\
\text { website improves, organic ranking of the } \\
\text { website will improve for the location based } \\
\text { keywords. }\end{array}$ & $\begin{array}{l}\text { Website ranking progressed } 7.27 \% \text { with the } \\
\text { improvement of online reputation. }\end{array}$ & Yes \\
\hline $\begin{array}{l}\text { Hypothesis-7: Organic ranking of a website is } \\
\text { proportional to organic traffic to a website }\end{array}$ & $\begin{array}{l}\text { According table-2, organic traffic was improved } \\
20.45 \% \text { and } 55.73 \% \text { in week } 7 \text { and week } 8 \\
\text { respectively with progression of organic ranking. }\end{array}$ & Yes \\
\hline
\end{tabular}

\section{Conclusion}

Search Engine Optimisation is an effective method to draw targeted traffic from search engines to a website, thereby increasing sales. The model has improved the ranking of a demo website in organic search results. However, due to its demo status, the website did not represent an actual business. As a result, links with high quality websites could not be established and reviews from actual users could not be obtained. The model was tested for two months which was a limited period only.

Ideally, this kind of research should be done on multiple websites which represent genuine businesses and for longer duration. Search engines update their organic ranking algorithm frequently and introduce new SEO factor. For this reason, long-term research can help design a more durable SEO model.

\section{References}

[1] Gudivada, V. N., Rao, D., \& Paris, J. (2015). Understanding search-engine optimization. IEEE Computer Society, 48(10), 43-52.

[2] Zhang, S., \& Cabage, N. (2016). Search engine optimization: Comparison of link building and social sharing. Journal of Computer Information System, 57(2), 148-149.

[3] Kumar, P. R., Singh, A. K., \& Mohan, A. (2013). Efficient methodologies to optimize website for link structure based search engines. Proceedings of the International Conference on Green Computing, Communication and Conservation of Energy. 
[4] Killoran, J. How to use search engine optimization techniques to increase website visibility. IEEE Transaction on Professional Communication, 56, 50-66.

[5] Zilincan, J., Gregus, M. (2015). Improving ranking of a website in search result - An experimental appraoch. Proceedings of the 10th International Conference on P2P, Parallel Grid, Cloud and Internet Computing (3PGCIC).

[6] Google Inc. Search engine optimization starter guide. (2016). Retrieved from https://static.googleusercontent.com/media/www.google.com/en//webmasters/docs/search-engineoptimization-starter-guide.pdf

[7] Fishkin, R. Beginner's Guide To SEO. (2016). Retrieved from https://moz.com/beginners-guide-to-seo.

[8] Lee, M. (2016). A complete local SEO guide for small business. Retrieved from https://searchenginewatch.com/2016/10/06/a-complete-local-seo-guide-for-small-businesses/

[9] Lee, S., \& Jang, W. (2016). Search engine optimization - A case study using the bibliographies of LG science land in Korea. Emerald Insight, 34(2), 197-206.

[10] The Webmaster Inc. Google ranking factors. The Webmaster Inc. (2017). Retrieved from https://www.thewebmaster.com/seo/google-ranking-factors/

[11] Cchanda, D. (2016). 205 Google ranking factors - Ultimate SEO checklist for 2016. Retrieved from https://mytasker.com/blog/google-ranking-factors/

[12] Martin, J. A. (2016). Top 6 SEO ranking factors of 2016. Retrieved from http://www.cio.com/article/3104104/search/top-6-seo-ranking-factors-of-2016.html

[13] Dean, B., (2016). Google's 200 Ranking Factor - Complete list. Retrieved from http://backlinko.com/google-ranking-factors

[14] Grabowski, P. (2013). 30 Most important google ranking factors a beginner should know. Retrieved from https://unamo.com/blog/seo/30-important-google-ranking-factors-beginner-know

[15] Basta, R. (2015). Why you need SSL to rank better in 2017 and how to set it. Retrieved 29 December from https://fourdots.com/blog/why-you-need-ssl-to-rank-better-in-2016-and-how-to-set-it-2169

[16] Dean, B. (2016). We analyzed 1 million google search results. Here's what we learned about SEO. Retrieved from: http://backlinko.com/search-engine-ranking

P. W. C. Prasad is an adjunct associate professor with the School of Computing and Mathematics at Charles Sturt University, Australia. Prior to this, he was a lecturer at the United Arab Emirates University in UAE, Multimedia University in Malaysia and also the Informatics Institute of Technology (IIT), Sri Lanka. He gained his undergraduate and postgraduate degrees from St Petersburg State Electrotechnical University in the early 90s and completed his PhD studies at the Multimedia University in Malaysia. He is an active researcher in the areas of computer architecture, digital systems, modelling and simulation. He has published more than 100 research articles in computing and engineering journals and conferences proceedings. He has co-authored two books entitled 'Digital Systems Fundamentals' and 'Computer Systems Organization and Architecture' published by Prentice Hall. He is a senior member of the IEEE Computer Society. 